\title{
Do androgen-directed therapies improve outcomes in prostate cancer patients undergoing radical prostatectomy? A systematic review and meta-analysis
}

\author{
Ameeta L. Nayak ${ }^{1}$; Anathea S. Flaman; Ranjeeta Mallick ${ }^{2}$; Luke T. Lavallée ${ }^{1,2,3}$; Dean A. \\ Fergusson $^{1,2}$; Ilias Cagiannos ${ }^{3}$; Chris Morash ${ }^{3}$; Rodney H. Breau ${ }^{1,2,3}$ \\ ${ }^{1}$ Faculty of Medicine, University of Ottawa, Ottawa, ON, Canada; ${ }^{2}$ Clinical Epidemiology Program, Centre for \\ Practice Changing Research, Ottawa Hospital Research Institute, Ottawa, ON, Canada; ${ }^{3}$ Division of Urology, \\ Department of Surgery, The Ottawa Hospital, Ottawa, ON, Canada
}

Funding: This study was supported by grant funding from the Ottawa Chapter of the TELUS Ride For Dad and the Nation Valley ARFD, the University of Ottawa Department of Surgery, and The Ottawa Hospital Academic Medical Organization.

Cite as: Nayak AL, Flaman AS, Mallick R, et al, et al. Do androgen directed therapies improve outcomes in prostate cancer patients undergoing radical prostatectomy? A systematic review and meta-analysis. Can Urol Assoc J 2021 January 8; Epub ahead of print. http://dx.doi.org/10.5489/cuaj.7041

Published online January 8, 2021

$* * *$

\section{Abstract}

Introduction: Approximately 50\% of patients with non-metastatic prostate cancer are treated with radical prostatectomy. While some men will be cured with surgery alone, a substantial proportion will experience cancer recurrence. Androgen-directed therapy (ADT) is an effective adjuvant therapy for patients treated with prostate radiation. Comparatively, the efficacy of ADT in surgical patients has not been well studied.

Methods: A systematic search of MEDLINE, Embase, and the Cochrane Library from inception to July 2020 was performed. Randomized trials comparing ADT with radical prostatectomy vs. prostatectomy alone in patients with clinically localized prostate cancer were included.

Neoadjuvant ADT and adjuvant ADT interventions were assessed separately. The primary outcomes were cancer recurrence-free survival (RFS) and overall survival (OS). Pathologic outcomes following neoadjuvant ADT were also evaluated.

Results: Fifteen randomized trials met eligibility criteria; 11 evaluated neoadjuvant ADT $(\mathrm{n}=2322)$ and four evaluated adjuvant ADT $(\mathrm{n}=5205)$. Neoadjuvant ADT (three months of treatment) did not improve RFS (hazard ratio [HR] 0.90, 95\% confidence interval [CI] 0.741.11) or OS (HR 1.22, 95\% CI 0.62-2.41). Neoadjuvant ADT significantly decreased the risk of 
positive surgical margins (relative risk [RR] 0.48, 95\% CI 0.41-0.56) and extraprostatic tumor extension (RR 0.75, 95\% CI 0.64-0.89). Adjuvant ADT improved RFS (HR 0.65, 95\% CI 0.450.93 ) but did not improve OS (HR 1.02, 95\% CI 0.84-1.24).

Conclusions: Neoadjuvant ADT causes a pathologic downstaging of prostate tumors, but has not been found to delay cancer recurrence nor extend survival. Few studies evaluated adjuvant ADT. Trials are needed to determine the benefits and harms of intermediate or long-term adjuvant ADT for radical prostatectomy patients.

\section{Introduction}

Approximately $50 \%$ of patients with non-metastatic prostate cancer are treated by radical prostatectomy. ${ }^{1}$ While some men will be cured with surgery alone, approximately $40 \%$ will experience cancer recurrence. ${ }^{2}$ The combination of conservative management of low-risk prostate cancer and aggressive surgical treatment of high-risk patients has resulted in a greater number of patients certain to experience cancer recurrence after surgery. ${ }^{3}$

Androgen directed therapy (ADT) is a hormonal mediated class of treatments that encompasses orchiectomy, gonadotropin-releasing hormone ( $\mathrm{GnRH})$ agonists/antagonists, androgen receptor antagonists, non-steroidal estrogens, and androgen-related enzyme inhibitors. ADT prolongs survival for patients with metastatic prostate cancer. ${ }^{4}$ Approximately $90 \%$ of these men respond initially to ADT, however, treatment resistance eventually occurs due to the emergence of ADT-resistant tumour cells. While ADT is not curative for patients with metastases, randomized clinical trials have consistently shown that 6 to 18 months of ADT improves survival for patients receiving pelvic radiation for non-metastatic disease. As such, ADT has become standard of care for high-risk men treated with primary radiation., ${ }^{5,6}$

Several observational studies suggest ADT may also benefit patients treated with surgery. In cohorts of radical prostatectomy patients, adjuvant ADT has been associated with improved cancer-specific survival as well as reduced clinical and PSA recurrence. ${ }^{7-10}$ Despite cohort studies showing a beneficial role for ADT when added to radical prostatectomy, clinical practice guidelines do not advocate adjuvant ADT following surgery (with the exception of those found to have lymph node metastases).

Thus, the objective of this study was to systematically review the literature for randomized controlled trials evaluating the use of ADT with radical prostatectomy for treatment of prostate cancer. Specifically, we examined whether ADT, administered before or immediately after radical prostatectomy improves survival and surgical outcomes when compared to radical prostatectomy alone in patients with clinically localized prostate cancer. 


\section{Methods}

\section{Protocol registration and eligibility}

The protocol for this review was registered on PROSPERO (no. CRD42019120866), in March of 2019. To guide our literature search strategy, we focused on radical prostatectomy patients (Population), androgen directed therapy (Intervention), compared to placebo or standard care (Comparison), for cancer related events (Outcome). Randomized controlled trials evaluating neoadjuvant (started prior to radical prostatectomy) and adjuvant (started after radical prostatectomy and prior to PSA recurrence) ADT were included. Androgen directed therapies included those aimed to decrease androgens (orchiectomy, GnRH agonists or antagonists, CYP17A1 inhibitors) or androgen receptor antagonists. We did not restrict inclusion to any specific dose, duration, or route of drug administration.

The primary outcome was cancer recurrence-free survival, including biochemical recurrence (i.e. PSA recurrence), local clinical recurrence, distant clinical metastasis, or receipt of salvage therapies such as radiotherapy. Secondary outcomes included overall survival, and for neoadjuvant studies, surgical margin status, pathologic tumour stage, and lymph node metastases. Where reported, the harms of therapy (hot flashes, anemia, cognitive impairment, fatigue, gynecomastia, osteoporosis, obesity, cardiovascular disease, and diabetes), and patient reported quality of life were captured and described.

\section{Information sources}

A comprehensive and systematic literature search of peer-reviewed, indexed databases MEDLINE, Embase, and the Cochrane Library was conducted to identify relevant studies. The search was last conducted on July 31, 2020.

\section{Search}

The search strategy was developed by an information specialist and a surgical urologic oncologist (Appendix). No language and date restrictions were imposed on full text articles; conference abstracts were limited to 2015 onward. Relevant historical cohort or prospective studies were included in the search criteria and reviewed at the full text stage but were removed in the final review. Other published works including letters, editorials, and comments were excluded. Literature and systematic review articles were also excluded, however, reference lists were sourced for additional studies.

\section{Study selection}

Titles and abstracts retrieved from the literature search were screened for inclusion by two independent reviewers (AN and AF). All duplicates were removed. The full text articles of potentially relevant titles and abstracts were retrieved and screened for final eligibility by the same reviewers. Any disagreements were resolved by consensus, or by a third-party reviewer (RB). Studies meeting eligibility criteria were included in the systematic review and studies 
reporting one or more of the outcomes of interest were included in the meta-analyses. If multiple publications pertaining to the same trial were identified, the most recent publication and data were used. The study selection was documented and reported using the Preferred Reporting Items for Systematic Reviews and Meta-analyses (PRISMA) flow diagram. ${ }^{11}$

\section{Data collection process}

The data extraction form was developed and pilot-tested by two independent reviewers (AN and AF). Data extraction was performed in duplicate and compared. Disagreements were reconciled by consensus and consultation with a third party (RB), when necessary.

\section{Data items}

Data items included: publication traits (year of publication, journal, authorship list, country, funding sources), study population (eligibility criteria, number of patients, age, race, comorbidities) cancer characteristics (grade, stage, pre-operative PSA), intervention (type of ADT, dose, route, duration, and timing of administration), comparator (standard of care versus placebo), and outcomes of interest (PSA recurrence, local recurrence, metastases, death, receipt of pelvic radiation, and adverse events). For neoadjuvant ADT trials, surgical outcomes (margin status, lymph node involvement, pathologic staging) were also collected. Cancer staging reported using the Whitmore-Jewett system was converted to the American Joint Committee on Cancer Tumour stage system as follows: Stage B (0-2) = pT2, Stage C (1-2) = pT3.

\section{Risk of bias in individual studies}

Two independent reviewers (AN and AF) evaluated the risk of bias for each included study. Guided by the Cochrane risk of bias tool, ${ }^{12}$ five domains were graded as "high risk", "moderate risk" or "low risk" for bias: randomization process, deviation from intended intervention, missing outcome data, measurement of the outcome, and selection of the reported result. Any disagreements were resolved through consensus or by a third party (RB). Risk of bias for each domain, outcome and included study were reported.

\section{Summary measures}

For dichotomous outcomes, summary measures were risk ratios with associated $95 \%$ confidence intervals. For continuous outcomes, summary measures were absolute mean difference with associated $95 \%$ confidence intervals. For time-to-event measures, hazard ratios were extracted from individual studies or calculated from the available data using previously described methods.$^{13}$ Forest plots were used to present the outcomes of individual studies and the pooled estimate of effect across all studies with the corresponding $95 \%$ confidence intervals. Quality of life outcomes were not pooled but described in the narrative analysis.

\section{Synthesis of results}


We used a random-effects model to perform all meta-analyses, as it provides a more conservative estimate than the fixed-effects model and makes more realistic assumptions regarding the existence of heterogeneity between studies. Pooling of data and data analysis was performed using RevMan 5.3 (Cochrane Collaboration, Oxford, United Kingdom). Neoadjuvant and adjuvant ADT were analyzed as separate interventions. Pre-planned subgroup analyses were performed, stratifying patients by type of ADT (GnRH agonist/antagonist, androgen receptor antagonists, orchiectomy, or combined treatments) and cancer stage (clinical TNM staging for ADT administered prior to surgery; pathologic TNM staging for ADT administered after surgery).

The heterogeneity of effect sizes (i.e. statistical heterogeneity) across included studies was examined using the $\mathrm{I}^{2}$ statistic, interpreted in categories of low (0-25\%), moderate (25-50\%) and substantial (50-100\%) heterogeneity.

\section{Risk of bias across studies}

Funnel plots were used to assess publication bias. The quality of evidence was assessed using The Grading of Recommendations Assessment, Developing, and Evaluation (GRADE) approach. ${ }^{14}$

\section{Results}

\section{Study selection}

Our systematic literature search identified 3,832 records. After removing 296 duplicates, 3,536 titles and abstracts were screened, of which 3,242 were deemed not relevant to the research question. Of the 294 full text articles, 15 trials described in 48 articles met our eligibility criteria and were included in quantitative analysis (Figure 1).

\section{Study characteristics}

A total of 11 RCTs evaluating neoadjuvant ADT and 4 RCTs evaluating adjuvant ADT published between 1980 and 2010 met our eligibility criteria. ${ }^{15-29}$ Seven trials originated in North America, 7 originated in Europe, and 1 trial included sites world-wide. Study characteristics are described in Table 1.

\section{Neoadjuvant ADT}

Eleven studies with a total of 2,322 patients investigated the effect of neoadjuvant ADT before radical prostatectomy compared to surgical treatment alone (Table 1). From these studies, recurrence-free survival, overall survival, surgical margin status, organ confinement of disease, and lymph node involvement were reported and evaluated.

\section{Recurrence free survival}


Recurrence-free survival was reported in 5 trials involving 1,277 patients (Table 1). PSA recurrence threshold varied between $0.1 \mathrm{ng} / \mathrm{mL}$ to $1.0 \mathrm{ng} / \mathrm{mL}$, and some trials also included local recurrence, metastases and death into a composite recurrence outcome (Appendix Table 1). Median follow-up ranged from 4 to 8 years. Overall, the pooled estimate demonstrates a small, but statistically insignificant reduction in post-operative recurrence with neoadjuvant ADT (pooled HR 0.90, 95\%CI 0.74-1.11), with low heterogeneity between studies $\left(\mathrm{Chi}^{2}=1.12, \mathrm{df}=4\right.$ $(\mathrm{P}=0.89), \mathrm{I}^{2}=0 \%$ ) (Figure 2 ).

\section{Overall survival}

Four studies involving 974 patients reported overall survival, from which two studies (339 patients) reported time to death. The pooled estimate from those two studies suggests there is no difference in overall survival between patients treated with 3-months of neoadjuvant ADT compared to surgery alone (pooled HR 1.22, 95\%CI 0.62-2.41) (Appendix Figure 1).

Additionally, neoadjuvant ADT did not reduce the risk of prostate cancer associated death (Appendix Figure 2).

\section{Positive surgical margins}

All eleven trials of neoadjuvant ADT examined surgical margins (Appendix Figure 3). The pooled estimate demonstrates neoadjuvant ADT for 3 to 6 months reduces the risk of positive surgical margins compared to no treatment (pooled RR 0.48; 95\%CI 0.41-0.56). There was low statistical heterogeneity between trials $\left(\mathrm{Chi}^{2}=14.3, \mathrm{df}=11(\mathrm{P}=0.22), \mathrm{I}^{2}=23 \%\right)$. A similar risk reduction was also found when stratifying studies according to type of ADT (Appendix Figure 3).

Longer durations of neoadjuvant treatment further decreased the risk of positive margins. However, these rates were not significantly different between 3 and 6 months of treatment (25.9\% with 3 months ADT versus $18.7 \%$ with 6 months ADT, $p=0.295){ }^{23}$

In studies that stratified patients by cancer stage, neoadjuvant ADT improved margins for both cT2 and cT3 prostate cancers. ${ }^{21-23}$ Positive margins ranged from $8 \%$ to $26 \%$ with neoadjuvant ADT compared to $34 \%$ to $47 \%$ without ADT in patients with cT2 disease, and ranged from $8 \%$ to $42 \%$ with neoadjuvant ADT compared to $33 \%$ to $76 \%$ without ADT in patients with cT3 disease.

\section{Pathologic extraprostatic extension (EPE)}

Eight studies investigated pathologic tumour stage, involving 1,710 patients (Table 1$)$. The administration of neoadjuvant ADT reduced the risk of EPE (pooled RR 0.75, 95\%CI 0.64-0.89), however there was substantial statistical heterogeneity in the findings $\left(\mathrm{Chi}^{2}=24.4, \mathrm{df}=8\right.$ $(\mathrm{P}=0.002), \mathrm{I}^{2}=67 \%$ ) (Appendix Figure 4 ). When stratifying trials according to type of ADT, only combination ADT (GnRH and androgen receptor antagonist) demonstrated a statistically 
significant reduction in EPE, however, these findings were also heterogenous (pooled RR 0.65, 96\%CI 0.51-0.82; $\left.\mathrm{Chi}^{2}=14.4, \mathrm{df}=4(\mathrm{P}=0.006), \mathrm{I}^{2}=72 \%\right)$.

\section{Pathologic lymph node metastases}

Six trials involving 1,395 patients investigated pathologic lymph node metastases. Overall, the reduction in lymph node metastases with neoadjuvant ADT was not statistically significant (pooled RR 0.67, 95\% CI 0.43-1.04) (Appendix Figure 5). The findings had low statistical heterogeneity $\left(\mathrm{Chi}^{2}=5.62, \mathrm{df}=5(\mathrm{P}=0.34), \mathrm{I}^{2}=11 \%\right)$. Similarly, there were no differences in distant metastases between patients receiving neoadjuvant ADT and those in the control group (Appendix Figure 6). Analysis of the three studies that used combination ADT demonstrated an overall reduction in lymph node metastases (pooled RR 0.61, 95\%CI 0.42-0.90) (Appendix Figure 5).

\section{Adverse events}

Two studies described side effects from ADT. The most common adverse effects of GnRH agonists were flushing and increased perspiration, ${ }^{17}$ while 3 out of 45 patients withdrew from bicalutamide due to gynaecomastia, mastodynia, and gastrointestinal intolerance. ${ }^{20}$ One death from acute myocardial infarction was also reported in a patient receiving ADT. ${ }^{17}$

\section{Adjuvant ADT}

Four trials evaluated adjuvant ADT following radical prostatectomy (Table 1). These trials evaluated bicalutamide for 2 years, long-term flutamide, long-term diethylstilbestrol, or longterm goserelin/orchiectomy.

\section{Recurrence free survival}

Pooled survival data of 4,906 patients from 3 trials demonstrated a significant benefit of adjuvant ADT on recurrence (pooled HR $0.65,95 \%$ CI $0.45-0.93$ ), but substantial heterogeneity was present $\left(\mathrm{Chi}^{2}=20.0, \mathrm{df}=3(\mathrm{P}=0.0002), \mathrm{I}^{2}=85 \%\right)$ (Figure 3$)$. The definition of recurrence varied between studies (Appendix Table 1). Patients treated with DES were not included in this analysis as recurrence was described in rate per 1,000 patient months.

Larger benefits of ADT were observed in patients with higher stages of disease. Among patients with pT3-T4, node negative disease, adjuvant ADT delayed recurrence (HR 0.51, 95\% CI 0.32-0.81) ${ }^{27}$ Similarly, marginal significance was achieved favouring ADT in patients with locally advanced disease (HR $0.85,95 \%$ CI $0.71-1.01$ ). ${ }^{26} \mathrm{In}$ lymph node positive patients, recurrence was also significantly reduced with adjuvant treatment (47\% vs. $86 \%$, HR 3.42 , 95\% CI 1.96-5.98, p<0.0001). ${ }^{29}$ 


\section{Overall survival}

Data pooled from the four included trials (5,205 patients) demonstrate no difference in survival between patients followed with observation and adjuvant hormone therapy (pooled HR 1.02, 95\%CI 0.84-1.24). The results between studies were moderately heterogenous $\left(\mathrm{Chi}^{2}=9.75, \mathrm{df}=5\right.$ $(\mathrm{P}=0.08), \mathrm{I}^{2}=49 \%$ ) (Appendix Figure 7).

The only study that found an improvement in survival included patients with nodepositive prostate cancer treated with orchiectomy or goserelin. ${ }^{29}$ At 11.9 years median follow up, death occurred in $36 \%$ of patients treated with ADT compared to $55 \%$ of control patients. No improvement in survival was observed in trials that used diethylstilbestrol or androgen receptor antagonists. $^{26,27}$

\section{Prostate cancer death}

Three trials involving 4,853 patients assessed prostate cancer death. The pooled estimate suggests there is a $40 \%$ reduction in death due to prostate cancer between patients treated with adjuvant $\mathrm{ADT}$ and control following $\mathrm{RP}$, but this difference was not statistically significant (pooled RR 0.60; 95\%CI 0.31-1.18, $\left.\mathrm{Chi}^{2}=13.45, \mathrm{df}=4(\mathrm{P}=0.009), \mathrm{I}^{2}=70\right)$ (Appendix Figure 8).

\section{Adverse events}

The most common side effects of adjuvant bicalutamide was breast pain $(73.7 \%$ treated vs. $7.6 \%$ placebo) and gynaecomastia (68.8\% treated vs. $8.3 \%$ placebo), resulting in the withdrawal of $29.3 \%$ and $10.0 \%$ of patients from the trial, respectively. ${ }^{26}$ Flutamide related side effects included nausea, vomiting, and hepatotoxicity, and were the major reason for withdrawal from treatment. ${ }^{27} \mathrm{~A}$ significantly greater proportion of patients treated with goserelin experienced hot flashes $(59 \%$ vs. $0 \%, \mathrm{p}<0.001)$, gynecomastia ( $22 \%$ vs. $2 \%, \mathrm{p}<0.01)$, gastrointestinal effects ( $26 \%$ vs. $6 \%, \mathrm{p}<0.01)$, hematologic effects $(20 \%$ vs. $4 \%, \mathrm{p}=0.02)$, and weight gain $(17 \%$ vs. $2 \%$, $\mathrm{p}=0.05)$. Increases in urinary frequency and nonspecific genitourinary symptoms were also observed, however all patients who experienced any adverse event were able to continue treatment. ${ }^{29}$ Death due to cardiovascular disease was slightly higher in patients treated with ADT (DES: $38.4 \%$ treated vs. $35.2 \%$ untreated; bicalutamide: $2.6 \%$ treated vs. $2.1 \%$ untreated; goserelin/orchiectomy: $4.3 \%$ treated vs. $2.0 \%$ untreated). ${ }^{26,28,29}$

\section{Risk of bias within studies}

The majority of the included studies scored as "some concerns" on the overall risk of bias assessment (Figure 4). Randomization and allocation concealment were adequately described in six trials. Two studies were centrally randomized by telephone, ${ }^{25,29}$ one study used block randomization through an external party, ${ }^{18}$ and two described computer randomization. ${ }^{19,26}$ Labrie et al. used a random permuted block randomization. ${ }^{21}$ Only two trials used a placebo to blind patients to their assigned intervention; ${ }^{26,28}$ all other studies used an observation arm as the control group. Deviations from the intended intervention were appropriately described in most 
studies; prevailing reasons for deviations included side-effects of treatment or patients not undergoing surgery. Ten studies used appropriate intention to treat analysis. Only one study did not document reasons for dropout or withdrawal. ${ }^{28}$

Bias varied within the studies according to the outcome of interest. Surgical pathology is dependent on the interpretation of the pathologist; while 4 studies blinded pathologists to the intervention, ${ }^{15,20,21,24}$ neoadjuvant hormone therapy alters the architecture of the cells and can be difficult for pathologists to interpret without the knowledge of receipt of treatment.

Recurrence free survival was determined based on a combination of PSA tests, clinical findings, and imaging findings, which rely on the interpretation of the physician. The Cochrane algorithm would classify this outcome as high risk, ${ }^{12}$ however, all studies followed appropriate clinical practices therefore we considered these outcomes to be only of some concern. Measurements of overall survival were not affected by knowledge of treatment received. Outcomes were not measured differently between intervention and comparator groups. Few studies had an available study protocol or were registered, however many trials had multiple reports that demonstrated consistent analysis between publications.

\section{Risk of bias across studies}

Publication bias was assessed using funnel plots (Appendix Figures 9 and 10). For neoadjuvant ADT trials, small asymmetry was seen in the funnel plots for recurrence free survival and positive surgical margins. No asymmetry was observed in the funnel plots for overall survival, organ confined disease, and lymph node involvement. For adjuvant ADT trials, slight asymmetry was found for all outcomes, suggesting small study effects favouring treatment with ADT. For overall survival, asymmetry was likely due to the different study populations, where highest benefit for overall survival with treatment occurred in patients with lymph node metastases.

\section{Strength of evidence}

The GRADE evidence profile is presented in Appendix Table 2. While the strength of evidence for most outcomes was low, the cumulative evidence for surgical margin status was high.

\section{Discussion}

Many patients will experience recurrence following radical prostatectomy. ${ }^{30}$ These patients have no preventative treatment options. Adjuvant pelvic radiation was previously considered to be an option for these patients; however, results of the ARTISTIC meta-analysis demonstrated adjuvant radiotherapy provided no additional benefit over early salvage radiotherapy (HR 0.95 , 95\% CI 0.75-1.21; $\mathrm{p}=0.70) .{ }^{31}$ Among potential alternatives, ADT may be considered. ADT is currently indicated for use in metastatic prostate cancer patients and as an adjunct to primary radiation for patients with non-metastatic prostate cancer, however, the utility of this treatment in surgical patients may not be well understood. 
Two systematic reviews and meta-analyses were published in 2009 and described ADT in patients undergoing radical prostatectomy. ${ }^{32,33}$ The collective evidence demonstrated a benefit of neoadjuvant ADT on surgical margin status, however neither neoadjuvant nor adjuvant ADT improved recurrence-free or overall survival. The findings from previous reviews were limited due to incomplete follow up in a number of trials. The current review has captured additional trials and final follow up results from previously described studies. More recently, Tosco et al. conducted a wide-ranging systematic review focused on recent publications evaluating systemic treatments in combination with primary radiation or prostatectomy. ${ }^{34}$ In that review, only 2 trials of ADT with radical prostatectomy were identified, neither comparing ADT to observation or placebo. ${ }^{34}$ Thus, this systematic review and meta-analysis sought to comprehensively examine the literature and summarize the available evidence surrounding the use of ADT with radical prostatectomy.

\section{Neoadjuvant ADT}

The meta-analysis of neoadjuvant ADT trials demonstrated that short-term hormone therapy (3 to 6 months) prior to prostatectomy improves surgical margin status and may lead to pathologic downstaging of tumours. Despite these pathologic improvements, short-term ADT provided no recurrence or survival benefits.

Longer durations of neoadjuvant ADT have demonstrated greater improvements in pathologic outcomes, with smaller tumour volumes and continued regression seen at 6-8 months of neoadjuvant treatment. ${ }^{23,35,36}$ It is possible that the absence of survival benefit is due to insufficient duration or intensity of ADT therapy, or that the studies were underpowered to show a difference in these outcomes.

There are at least two ongoing trials investigating neoadjuvant ADT in high risk prostate cancer patients compared to prostatectomy alone; one studying the androgen receptor antagonist apalutamide, and the other studying combinations of ADT (Appendix Table 3) ${ }^{37}$ Like the trials included in this review, neoadjuvant ADT durations being examined are between 3-6 months. One of the limitations of neoadjuvant studies is the necessary delay in surgical treatment required. For longer durations of treatment, an adjuvant or combined neoadjuvant/adjuvant approach may be preferred.

\section{Adjuvant ADT}

Only four clinical trials evaluated long-term survival outcomes of adjuvant ADT following radical prostatectomy. Although no improvements in overall survival were observed, there was delayed recurrence, particularly among patients with high risk of recurrence. Remarkably, the most recent results of these trials were published over a decade ago, and many contemporary methods of ADT have not been evaluated. Three of the four trials have limited relevance to contemporary clinical practice as they examined treatment with either synthetic non-steroidal estrogen or androgen receptor antagonists at doses that are not currently recommended. The 
heterogeneity between the few studies examining adjuvant ADT limits our ability to make definitive conclusions regarding the utility of this treatment. In the absence of contemporary clinical trials, several large cohort studies have found that patients treated with immediate adjuvant ADT had delayed metastasis, and prolonged recurrence-free and cancer-specific survival, especially in higher risk patients. ${ }^{7-9}$ Additionally, randomized clinical trials have shown 6-36 months of ADT prolongs survival of patients receiving primary radiation. ${ }^{38-40}$ Therefore, modern trials are needed to determine if ADT in the post-operative setting is beneficial.

Currently, there are few trials evaluating adjuvant therapy following radical prostatectomy publicly registered on clinicaltrial.gov (Appendix Table 3). One, registered in Russia and China, has been successfully completed (NCT01753297). This study evaluates the effect of 9 months of triptorelin immediately following prostatectomy in high-risk prostate cancer patients. Results from this study have yet to be published. Two other studies evaluating disease recurrence following longer durations of ADT (leuprolide acetate or apalutamide) are ongoing, with final reports expected in 2027.

\section{Salvage ADT}

A number of trials suggest some benefit of ADT as a salvage therapy. The ARTS trial investigated treatment with dutasteride in 294 patients with biochemical failure following radical prostatectomy or radiation therapy. ${ }^{41}$ Over the 24 -month treatment period, compared to placebo, salvage dutasteride significantly delayed PSA doubling time (RR 0.34; 95\%CI 0.23-0.50) and disease recurrence (RR 0.41; 95\%CI 0.25-0.67), (defined as PSA doubling time $\leq 3$ months, PSA $>20 \mathrm{ng} / \mathrm{mL}$ for subjects who underwent radiotherapy or PSA $>10 \mathrm{ng} / \mathrm{mL}$ for subjects who underwent prostatectomy with $\geq 50 \%$ increase from baseline, clinical recurrence, metastatic disease, or additional prostate cancer rescue therapy). ${ }^{41}$

The timing of salvage treatment has also been shown to influence survival outcomes. One study evaluated the effects of hormone deprivation in 120 men with detectable PSA following prostatectomy. ${ }^{42}$ Patients were either treated with two years of finasteride or observed for 1 year and treated with finasteride for the subsequent year. Though not statistically significant, fewer recurrences were observed in the early treatment group (12\% vs $19 \%) .{ }^{42}$ In another study of men with PSA relapse after curative treatment or disease not suitable for treatment, those who immediately received ADT had better overall survival compared to those who received ADT after 2 years from randomization (HR 0.55, 95\%CI 0.30-1.00). ${ }^{43}$ To our knowledge, there are currently no ongoing trials investigating the use of ADT as a salvage monotherapy following prostatectomy, however, trials using combinations of ADT with salvage radiation therapy and/or chemotherapy are ongoing.

\section{Other systemic treatments}

The peri-operative use of non-ADT treatments has been investigated and is an emerging area of research. These therapies include chemotherapy, immunotherapy, and poly ADP ribose 
polymerase (PARP) inhibitors, and are being studied both with and without concomitant ADT. ${ }^{34}$ The use of chemotherapy alone in patients undergoing prostatectomy did not provide survival benefit, while initial results suggest combined chemotherapy and hormone therapy may improve relapse-free survival. ${ }^{44,45}$ Small trials of vaccine-based immunotherapies and checkpoint inhibitors in localized prostate cancer have shown these therapies result in histologic tumour response, however, there are no available data on long term outcomes at this time. ${ }^{46}$

\section{Limitations}

Study level

It is important to recognize that the majority of the studies included in this review were found to have some risk or high risk of bias. The findings presented may be influenced by lack of blinding, patient dropouts and missing outcome data. Of note, the Early Prostate Cancer study, the largest trial included in this review, has a number of issues that contribute to the heterogeneity of our findings. ${ }^{26}$ A small proportion of patients who had been treated with radiation therapy were included in the comparison, and North American sites of the trial followed different protocols (primarily, excluding patients with lymph node involvement). ${ }^{26}$ Moreover, many of these trials evaluated older ADT agents including anti-androgen monotherapy which are currently not recommended for use in the clinical setting. Overall, eight of the eleven neoadjuvant ADT trials and only one of the four adjuvant ADT trials examined current methods of androgen directed therapy (orchiectomy, GnRH agonist/antagonist).

Review level

Disease recurrence and overall survival were reported either as dichotomous outcomes at the final follow up or as survival curves. Most of the survival curves presented did not provide the number at risk at interval time points; as such, it was not feasible to estimate the number of events at a common time point between studies. Thus, the relative risk of death and recurrence incorporates data from a range of time points spanning several years. While robust statistical measures were used to extract data from Kaplan Meier curves, these methods still require estimations of the original curves and may lead to some imprecision in calculated hazard ratios. For most studies investigating neoadjuvant ADT, time from randomization to surgery was not reported. Two studies indicated patients who did not receive ADT underwent surgery approximately 6 weeks after randomization, and patients receiving ADT underwent surgery approximately 1 week following treatment cessation. ${ }^{19,21}$ This may result in skewed survival outcomes favouring neoadjuvant ADT. Finally, patient populations and interventions varied widely between studies, particularly among the four adjuvant ADT trials. Different disease stages, forms of ADT, and length of treatment were considered in this review. Besides the limitation of the small number of trials, the heterogeneity between studies suggests a true estimate of the effect of adjuvant ADT cannot be confidently determined. 


\section{Conclusions}

Based on the available literature, short-term neoadjuvant ADT causes a pathologic downstaging of prostate tumours but does not reduce the risk of cancer recurrence or extend survival. The available studies evaluating adjuvant ADT are heterogeneous, however suggest a potential role of ADT in delaying disease recurrence. Adverse events associated with peri-operative ADT are generally tolerable by patients and may be reversible upon ADT cessation. Further trials are needed to evaluate the benefits and harms of ADT in surgical patients. 


\section{References}

1. Cooperberg MR, Broering JM, Carroll PR. Time trends and local variation in primary treatment of localized prostate cancer. J Clin Oncol 2010;28:1117-23.

2. Montroy J, Elzayat E, Morash C, et al. Long-term patient outcomes from the first year of a robotic surgery program using multi-surgeon implementation. Can Urol Assoc J 2018;12:3843.

3. Witherspoon L, Lau JL, Breau RH, et al. Reducing overtreatment of prostate cancer by radical prostatectomy in Eastern Ontario: a population-based cohort study. CMAJ Open. 2018;6:E197-E201.

4. Wilt TJ, MacDonald R, Rutks I, et al. Systematic review: comparative effectiveness and harms of treatments for clinically localized prostate cancer. Ann Intern Med 2008;148:43548.

5. Sanda MG, Cadeddu JA, Kirkby E, et al. Clinically localized prostate cancer: AUA/ASTRO/SUO guideline. Part I: risk stratification, shared decision making, and care options. J Urol 2018;199:683-90.

6. Voog JC, Paulus R, Shipley WU, et al. Cardiovascular mortality following short-term androgen deprivation in clinically localized prostate cancer: an analysis of RTOG 94-08. Eur Urol 2016;69:204-10.

7. Siddiqui SA, Boorjian SA, Blute ML, et al. Impact of adjuvant androgen deprivation therapy after radical prostatectomy on the survival of patients with pathological T3b prostate cancer. BJU Int 2011;107:383-8.

8. Siddiqui SA, Boorjian SA, Inman B, Bagniewski S, Bergstralh EJ, Blute ML. Timing of androgen deprivation therapy and its impact on survival after radical prostatectomy: a matched cohort study. J Urol 2008;179:1830-7.

9. Moul JW, Wu H, Sun L, et al. Early versus delayed hormonal therapy for prostate specific antigen only recurrence of prostate cancer after radical prostatectomy. J Urol 2004;171:11417.

10. Sato YT, Fukuhara H, Suzuki M, et al. Long-term results of radical prostatectomy with immediate adjuvant androgen deprivation therapy for pT3N0 prostate cancer. BMC Urol 2014;14:13.

11. Moher D, Liberati A, Tetzlaff J, et al. Preferred reporting items for systematic reviews and meta-analyses: The PRISMA statement. BMJ 2009;339:b2535.

12. Sterne JAC, Savović J, Page MJ, et al. RoB 2: A revised tool for assessing risk of bias in randomised trials. BMJ 2019;366:14898.

13. Tierney JF, Stewart LA, Ghersi D, et al. Practical methods for incorporating summary timeto-event data into meta-analysis. Trials 2007;8:16.

14. Schünemann H, Higgins J, Vist G, et al. Chapter 14: Completing 'Summary of findings' tables and grading the certainty of the evidence. In: Higgins J, Thomas J, Chandler J, et al., eds. Cochrane Handbook for Systematic Reviews of Interventions Version 6.0 (Updated July 2019). Cochrane; 2019. www.training.cochrane.org/handbook.

15. Aus G, Abrahamsson PA, Ahlgren G, et al. Three-month neoadjuvant hormonal therapy before radical prostatectomy: a 7-year follow-up of a randomized controlled trial. BJU Int 2002;90:561-6. 
16. Dalkin BL, Ahmann FR, Nagle R, et al. Randomized study of neoadjuvant testicular androgen ablation therapy before radical prostatectomy in men with clinically localized prostate cancer. J Urol 1996;155:1357-60.

17. Prezioso D, Lotti T, Polito M, et al. Neoadjuvant hormone treatment with leuprolide acetate depot $3.75 \mathrm{mg}$ and cyproterone acetate, before radical prostatectomy: A randomized study. Urol Int 2004;72:189-95.

18. Gravina GL, Festuccia C, Galatioto GP, et al. Surgical and biologic outcomes after neoadjuvant bicalutamide treatment in prostate cancer. Urology 2007;70:728-33.

19. Klotz LH, Goldenberg SL, Jewett MAS, et al. Long-term followup of a randomized trial of 0 versus 3 months of neoadjuvant androgen ablation before radical prostatectomy. $J$ Urol 2003;170:791-4.

20. Scattoni V, Montironi R, Mazzucchelli R, et al. Pathological changes of high-grade prostatic intraepithelial neoplasia and prostate cancer after monotherapy with bicalutamide $150 \mathrm{mg}$. BJU Int 2006;98:54-8.

21. Labrie F, Cusan L, Gomez JL, et al. Neoadjuvant hormonal therapy: The Canadian experience. Urology 1997;49:S56-S64.

22. Schulman CC, Debruyne FMJ, Forster G, et al. 4-year follow-up results of a European prospective randomized study on neoadjuvant hormonal therapy prior to radical prostatectomy in T2-3N0M0 prostate cancer. Eur Urol 2000;38:706-13.

23. Selli C, Montironi R, Bono A, et al. Effects of complete androgen blockade for 12 and 24 weeks on the pathological stage and resection margin status of prostate cancer. J Clin Pathol 2002;55:508-13.

24. Soloway MS, Pareek K, Sharifi R, et al. Neoadjuvant androgen ablation before radical prostatectomy in cT2bNxMo prostate cancer: 5-year results. J Urol 2002;167:112-6.

25. Yee DS, Lowrance WT, Eastham JA, et al. Long-term follow-up of 3-month neoadjuvant hormone therapy before radical prostatectomy in a randomized trial. BJU Int 2010;105:18590.

26. Iversen P, McLeod DG, See WA, et al. Antiandrogen monotherapy in patients with localized or locally advanced prostate cancer: final results from the bicalutamide Early Prostate Cancer programme at a median follow-up of 9.7 years. BJU Int 2010;105:1074-81.

27. Wirth MP, Weissbach L, Marx FJ, et al. Prospective randomized trial comparing flutamide as adjuvant treatment versus observation after radical prostatectomy for locally advanced, lymph node-negative prostate cancer. Eur Urol 2004;45:267-70.

28. Byar D. VACURG studies of post-prostatectomy survival. Scand J Urol Nephrol Suppl 1980;55:113-6.

29. Messing EM, Manola J, Yao J, et al. Immediate versus deferred androgen deprivation treatment in patients with node-positive prostate cancer after radical prostatectomy and pelvic lymphadenectomy. Lancet Oncol 2006;7:472-9.

30. Kattan MW, Wheeler TM, Scardino PT. Postoperative nomogram for disease recurrence after radical prostatectomy for prostate cancer. J Clin Oncol 1999;17:1499-507.

doi:10.1200/JCO.1999.17.5.1499

31. Vale CL, Fisher D, Kneebone A, et al. Adjuvant or early salvage radiotherapy for the treatment of localised and locally advanced prostate cancer: a prospectively planned systematic review and meta-analysis of aggregate data. Lancet 2020;S0140-6736. 
32. Shelley MD, Kumar S, Coles B, et al. Adjuvant hormone therapy for localised and locally advanced prostate carcinoma: a systematic review and meta-analysis of randomised trials. Cancer Treat Rev 2009;35:540-6.

33. Shelley MD, Kumar S, Wilt T, et al. A systematic review and meta-analysis of randomised trials of neo-adjuvant hormone therapy for localised and locally advanced prostate carcinoma. Cancer Treat Rev 2009;35:9-17.

34. Tosco L, Briganti A, D'Amico AV, et al. Systematic review of systemic therapies and therapeutic combinations with local treatments for high-risk localized prostate cancer. Eur Urol 2019;75:44-60.

35. Gleave ME, Goldenberg SL, Chin JL, et al. Randomized comparative study of 3 versus 8month neoadjuvant hormonal therapy before radical prostatectomy: Biochemical and pathological effects. J Urol 2001;166:500-7.

36. Van der Kwast TH, Têtu B, Candas B, et al. Prolonged neoadjuvant combined androgen blockade leads to a further reduction of prostatic tumor volume: three versus six months of endocrine therapy. Urology 1999;53:523-29.

37. Sterling J, Chua K, Patel H, et al. Interim analysis of phase 2 randomized prospective study on neoadjuvant apalutamide/abiraterone acetate with prednisone and the feasibility of performing nerve-sparing radical prostatectomy in men with high-risk prostate cancer (NCT02949284). J Urol 2020;203:e249.

38. Bolla M, De Reijke TM, Van Tienhoven G, et al. Duration of androgen suppression in the treatment of prostate cancer. N Engl J Med 2009;360:2516-27.

39. Bolla M, Gonzalez D, Warde P, et al. Improved survival in patients with locally advanced prostate cancer treated with radiotherapy and goserelin. N Engl J Med 1997;337:295-300.

40. D’Amico AV, Chen MH, Renshaw AA, et al. Androgen suppression and radiation vs radiation alone for prostate cancer: A randomized trial. JAMA 2008;299:289-95.

41. Schröder F, Bangma C, Angulo JC, et al. Dutasteride treatment over 2 years delays prostatespecific antigen progression in patients with biochemical failure after radical therapy for prostate cancer: Results from the randomised, placebo-controlled Avodart After Radical Therapy for Prostate Cancer Study (ARTS). Eur Urol 2013;63:779-87.

42. Andriole G, Lieber M, Smith J, et al. Treatment with finasteride following radical prostatectomy for prostate cancer. Urology 1995;45:491-7.

43. Duchesne GM, Woo HH, Bassett JK, et al. Timing of androgen-deprivation therapy in patients with prostate cancer with a rising PSA (TROG 03.06 and VCOG PR 01-03 [TOAD]): a randomised, multicentre, non-blinded, phase 3 trial. Lancet Oncol 2016;17:72737.

44. Eastham JA, Heller G, Halabi S, et al. CALGB 90203 (Alliance): Radical prostatectomy with or without neoadjuvant chemohormonal therapy in men with clinically localized, high risk prostate cancer. J Urol 2019;201:e997.

45. Fizazi K, Faivre L, Lesaunier F, et al. Androgen deprivation therapy plus docetaxel and estramustine versus androgen deprivation therapy alone for high-risk localised prostate cancer (GETUG 12): a phase 3 randomised controlled trial. Lancet Oncol 2015;16:787-94.

46. Patel D, McKay R, Parsons JK. Immunotherapy for localized prostate cancer: the next frontier? Urol Clin North Am 2020;47:443-56. 


\section{Figures and Tables}

Fig. 1. Selection flow diagram. ADT: androgen directed therapy; RCT: randomized controlled trial.

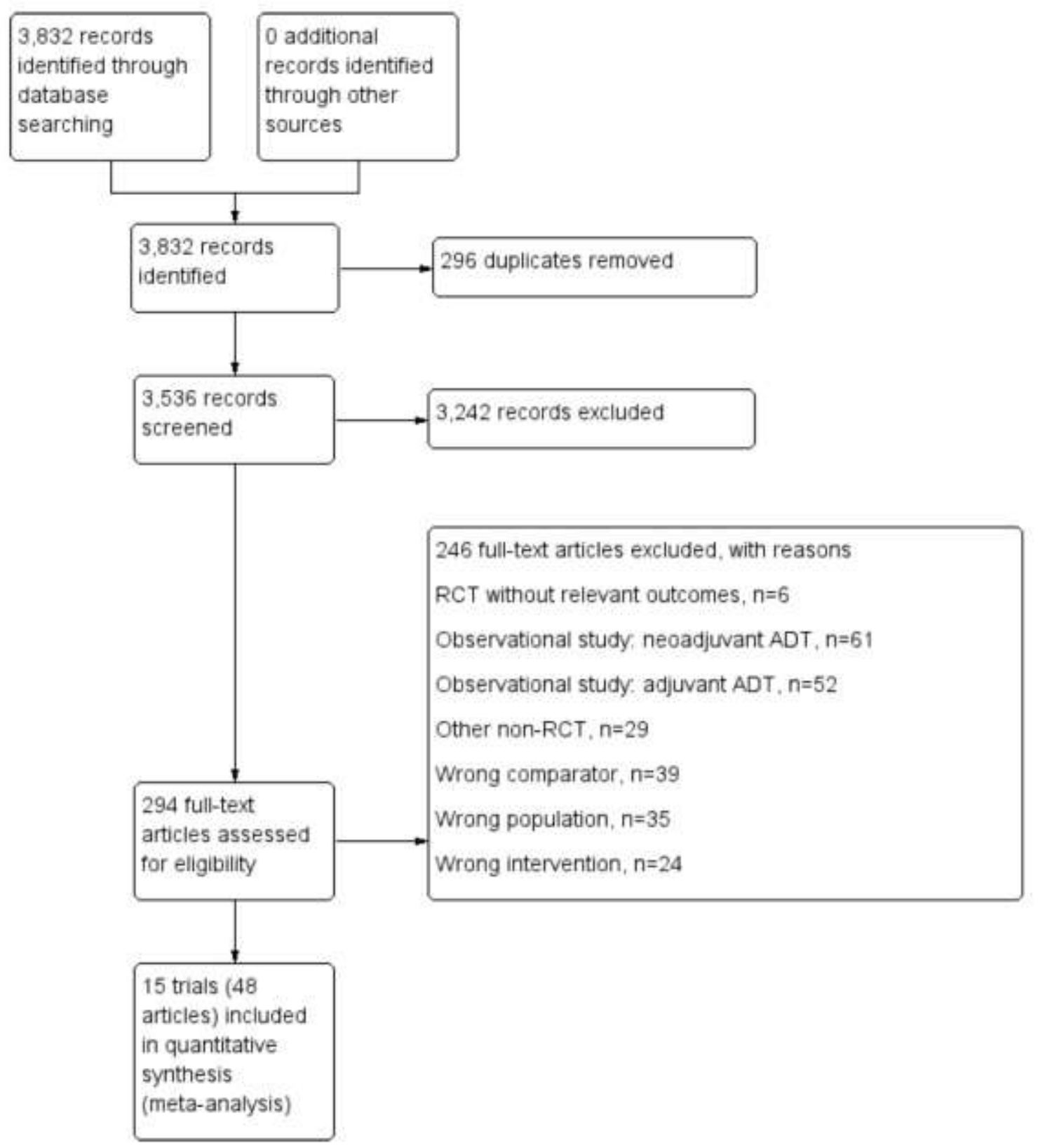


Fig. 2. Forest plot of hazard ratios of recurrence-free survival for neoadjuvant androgen-directed therapy (ADT) with prostatectomy (RP) vs. RP alone. CI: confidence interval.

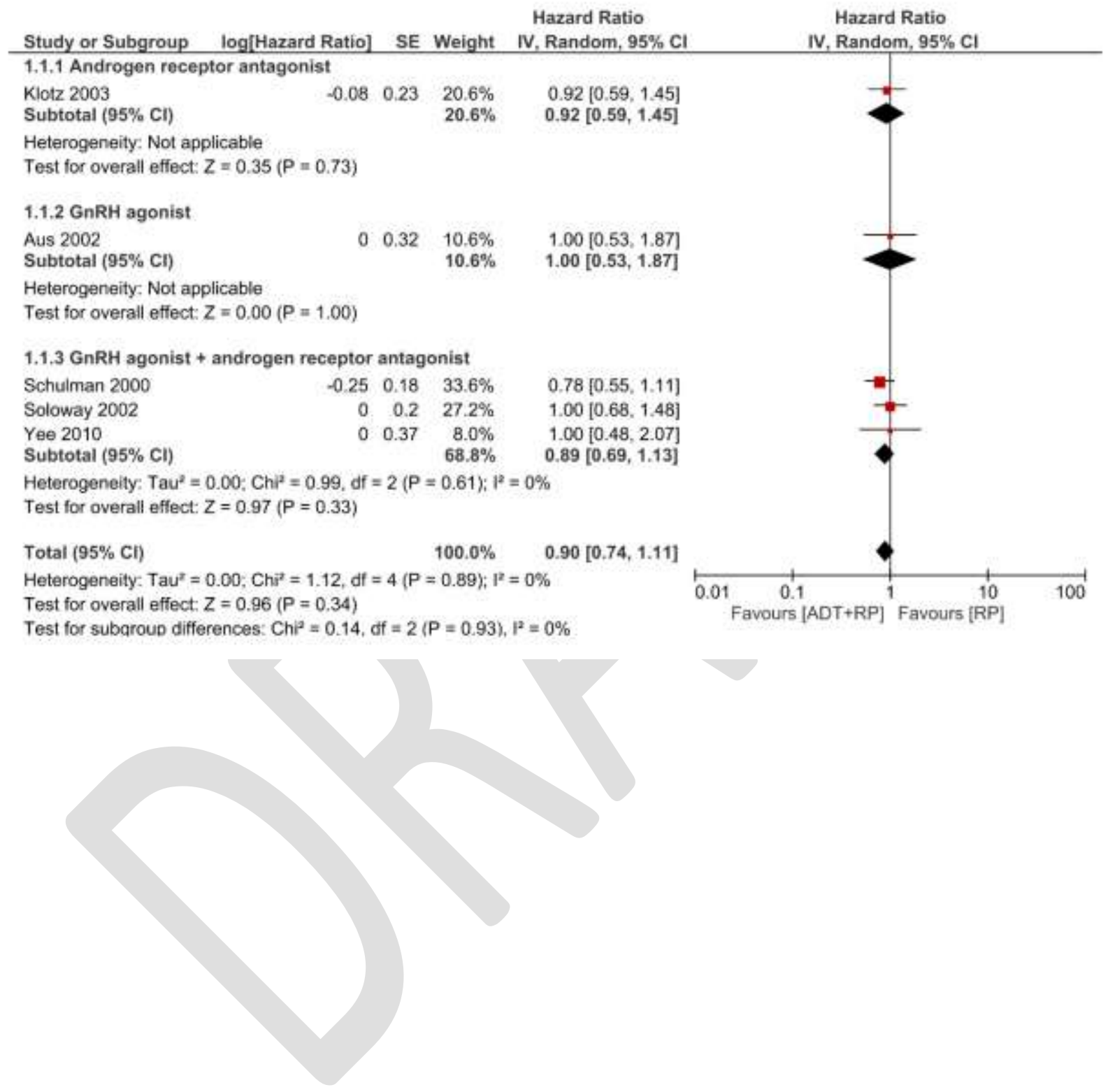


Fig. 3. Forest plot of hazard ratios of recurrence-free survival for adjuvant androgen-directed therapy (ADT) with prostatectomy (RP) vs. RP alone. "Iversen 2010a corresponds to clinically localized prostate cancer; Iversen $2010 \mathrm{~b}$ corresponds to locally advanced prostate cancer. CI: confidence interval.

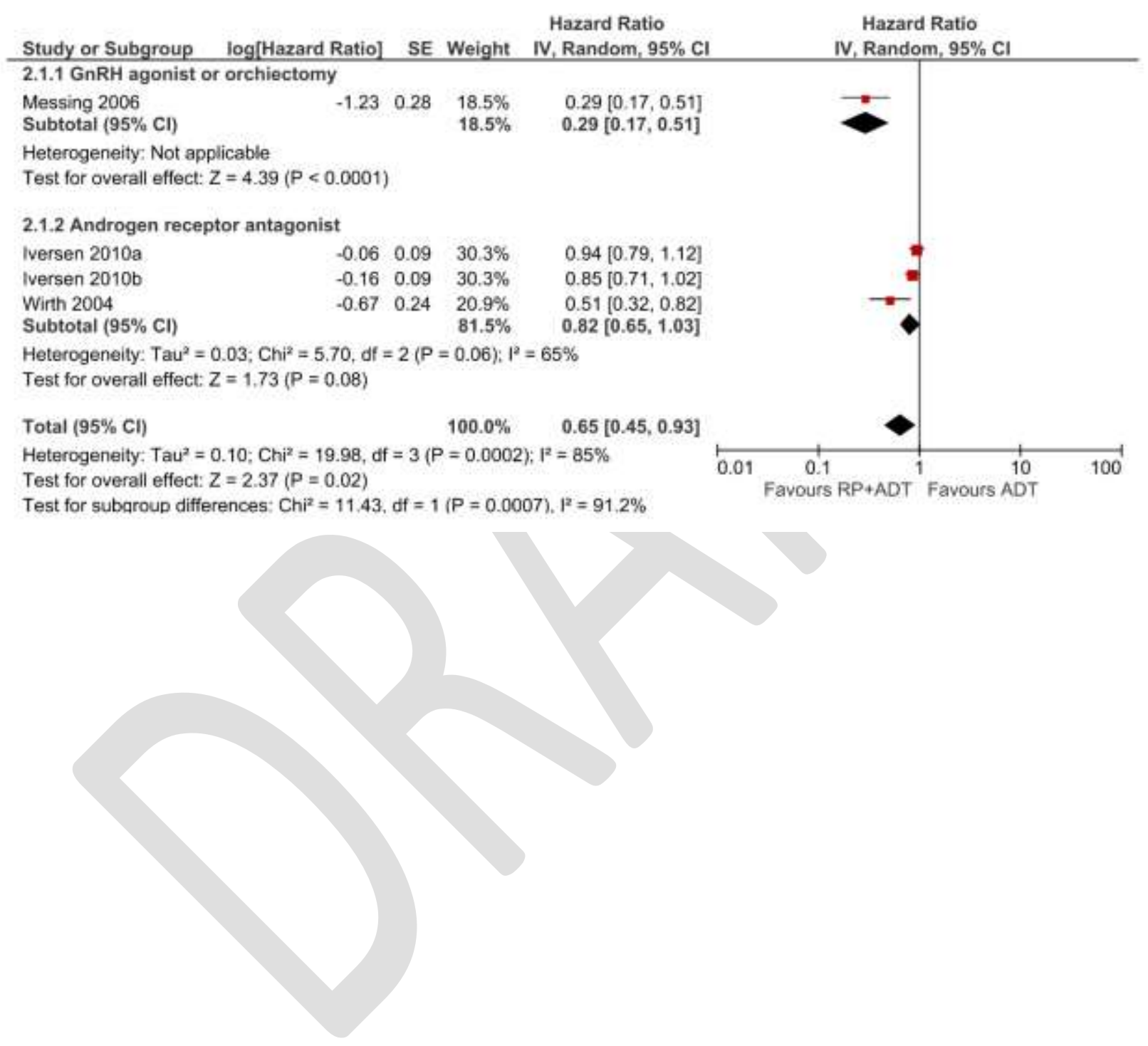


Fig. 4. Risk of bias of included studies

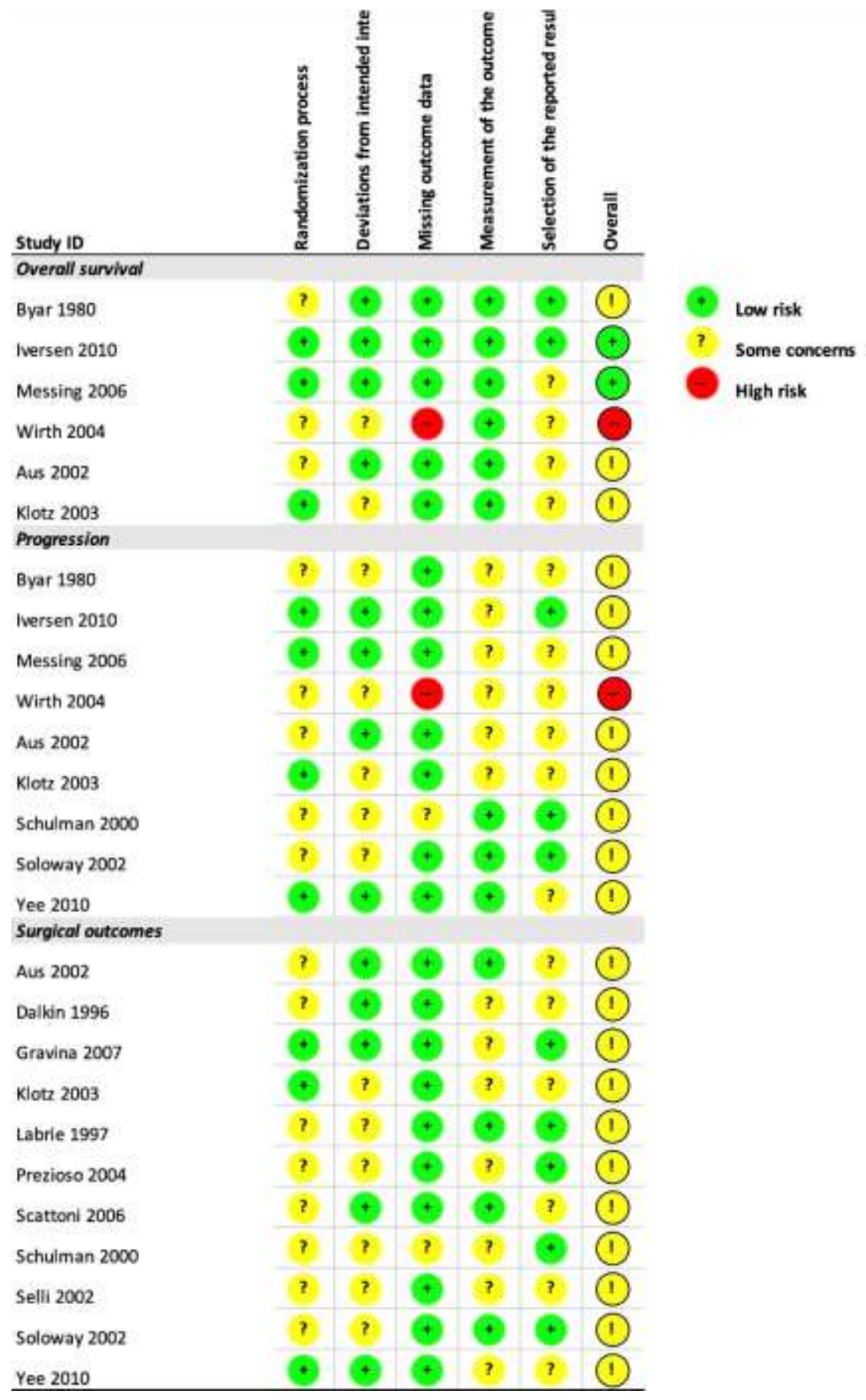




\begin{tabular}{|c|c|c|c|c|c|c|}
\hline $\begin{array}{l}\text { Author } \\
\text { (year) }\end{array}$ & $\begin{array}{c}\text { Country } \\
\text { (ies) }\end{array}$ & Patient population & $\begin{array}{c}\text { Patients } \\
\text { randomized }(\mathbf{n})\end{array}$ & Treatment & Comparator & Outcomes assessed \\
\hline \multicolumn{7}{|c|}{ Neoadjuvant ADT } \\
\hline \multicolumn{7}{|c|}{ GnRH agonist } \\
\hline Aus $(2002)^{15}$ & $\begin{array}{l}\text { Sweden, } \\
\text { Denmark }\end{array}$ & $\begin{array}{c}\text { T1b-T3aNXM0 } \\
\text { Age }<75 \\
>10 \text {-year life } \\
\text { expectancy }\end{array}$ & $\begin{array}{c}126 \\
\text { (initial report: } \\
112)\end{array}$ & $\begin{array}{l}\text { Triptorelin } 3.75 \mathrm{mg} \text { IM monthly }(+ \\
\text { cyproterone acetate 50mg BID } 1 \\
\text { week before and } 2 \text { weeks after first } \\
\text { injection for prophylaxis against } \\
\text { flare) for } 3 \text { months, followed by RP } \\
(n=63)\end{array}$ & $\begin{array}{c}\mathrm{RP} \\
(\mathrm{n}=63)\end{array}$ & $\begin{array}{ll}- & \text { PSM } \\
- & \text { OS } \\
- & \text { RFS } \\
- & \text { Rate of adjuvant } \\
& \text { therapy }\end{array}$ \\
\hline $\begin{array}{l}\text { Dalkin } \\
(1996)^{16}\end{array}$ & USA & $\begin{array}{l}\text { cT1c, T2a or T2b } \\
\text { PSA }>4.0 \mathrm{ng} / \mathrm{ml} \\
>10 \text {-year projected } \\
\text { survival }\end{array}$ & $\begin{array}{c}61 \\
\text { (5 did not } \\
\text { undergo } \\
\text { surgery) }\end{array}$ & $\begin{array}{c}\text { Goserelin 3.6ng SC monthly for } 3 \\
\text { months, followed by RP with } \\
\text { bilateral PLND } \\
(\mathrm{n}=28)\end{array}$ & $\begin{array}{c}\text { RP with bilateral } \\
\text { PLND } \\
(\mathrm{n}=28)\end{array}$ & - Surgical pathology \\
\hline $\begin{array}{l}\text { Prezioso } \\
(2004)^{17}\end{array}$ & Italy & $\begin{array}{l}\text { Histopathologically } \\
\text { proven prostatic } \\
\text { carcinoma } \\
\text { T1a-T2b } \\
>5 \text {-year life } \\
\text { expectancy } \\
\text { WHO performance } \\
\text { status } \leq 2\end{array}$ & $\begin{array}{l}183 \text { randomized } \\
\text { (16 not included } \\
\text { in analysis) }\end{array}$ & $\begin{array}{c}\text { Leuprolide acetate } 3.75 \mathrm{mg} \mathrm{IM} \\
\text { monthly for } 3 \text { months, followed by } \\
\text { RP with PLND } \\
(\mathrm{n}=81)\end{array}$ & $\begin{array}{l}\text { RP with PLND } \\
\quad(\mathrm{n}=86)\end{array}$ & $\begin{array}{ll}- & \text { PSM } \\
- & \text { Downstaging } \\
- & \text { Tumour histology } \\
- & \text { Perioperative } \\
& \text { outcomes }\end{array}$ \\
\hline \multicolumn{7}{|c|}{ Androgen receptor antagonist } \\
\hline $\begin{array}{l}\text { Gravina } \\
(2007)^{18}\end{array}$ & Italy & cT2-T3a & 119 & $\begin{array}{l}\text { Bicalutamide } 150 \mathrm{mg} \text { daily for } 4 \\
\text { months, followed by RP }\end{array}$ & $\begin{array}{c}\mathrm{RP} \\
(\mathrm{n}=58)\end{array}$ & - PSM \\
\hline
\end{tabular}




\begin{tabular}{|c|c|c|c|c|c|c|}
\hline & & $\begin{array}{l}\text { No previous } \\
\text { hormonal, radio- or } \\
\text { chemotherapy } \\
\text { No previous } \\
\text { investigational } \\
\text { agents } \\
>10 \text {-year life } \\
\text { expectancy }\end{array}$ & & $(\mathrm{n}=61)$ & & $\begin{array}{ll}- & \text { Tumor marker } \\
\text { expression }\end{array}$ \\
\hline $\begin{array}{l}\text { Klotz } \\
(2003)^{19}\end{array}$ & Canada & $\begin{array}{c}\text { cT1-T2 } \\
\text { Negative bone scan } \\
\text { PSA }<50 \mathrm{ng} / \mathrm{ml} \\
\text { PAP }<\text { twice normal } \\
(<1.8 \mathrm{u} / \mathrm{L})\end{array}$ & $\begin{array}{c}213 \\
(13 \text { did not } \\
\text { undergo } \\
\text { surgery })\end{array}$ & $\begin{array}{c}\text { Cyproterone acetate } 300 \mathrm{mg} \text { daily for } \\
3 \text { months, followed by RP } \\
(\mathrm{n}=104)\end{array}$ & $\begin{array}{c}\mathrm{RP} \\
(\mathrm{n}=96)\end{array}$ & $\begin{array}{l}- \text { PSM } \\
- \text { Downstaging } \\
- \text { OS } \\
- \text { RFS }\end{array}$ \\
\hline $\begin{array}{l}\text { Scattoni } \\
(2006)^{20}\end{array}$ & Italy & $\begin{array}{c}\text { cT1c/T2a } \\
\text { Gleason score } \leq 8 \\
\text { with HGPIN }\end{array}$ & 90 & $\begin{array}{c}\text { Bicalutamide } 150 \mathrm{mg} \text { daily for } 3 \\
\text { months, followed by RP with } \\
\text { bilateral PLND } \\
(\mathrm{n}=45)\end{array}$ & $\begin{array}{c}\text { RP with bilateral } \\
\text { PLND } \\
(\mathrm{n}=45)\end{array}$ & $\begin{array}{ll}- & \text { PSM } \\
- & \text { PSA } \\
- & \text { Tumor } \\
& \text { characteristics }\end{array}$ \\
\hline \multicolumn{7}{|c|}{ GnRH agonist + androgen receptor antagonist } \\
\hline $\begin{array}{l}\text { Labrie } \\
(1997)^{21}\end{array}$ & Canada & $\begin{array}{l}\text { Histopathologically } \\
\text { proven } \\
\text { adenocarcinoma of } \\
\text { prostate } \\
\text { Localized PCa } \\
>10 \text {-year life } \\
\text { expectancy }\end{array}$ & 161 & $\begin{array}{c}\text { Depo-lupron } 7.5 \mathrm{mg} \text { IM every } 28 \\
\text { days + flutamide } 250 \mathrm{mg} \text { TID for } 3 \\
\text { months, followed by RP } \\
(\mathrm{n}=90)\end{array}$ & $\begin{array}{c}\mathrm{RP} \\
(\mathrm{n}=71)\end{array}$ & $\begin{array}{ll}- & \text { PSM } \\
- & \text { Organ confined } \\
& \text { disease } \\
- & \text { Downstaging }\end{array}$ \\
\hline
\end{tabular}




\begin{tabular}{|c|c|c|c|c|c|c|}
\hline $\begin{array}{l}\text { Schulman } \\
(2000)^{22}\end{array}$ & $\begin{array}{c}\text { Netherlands } \\
\text { Belgium }\end{array}$ & $\begin{array}{c}\text { T2-3 NxM0 } \\
\text { PSA<100ng/ml }\end{array}$ & $\begin{array}{c}487 \\
\text { (21 not eligible, } \\
64 \text { not included } \\
\text { in analysis) }\end{array}$ & $\begin{array}{l}\text { Goserelin } 3.6 \mathrm{mg} \text { SC monthly }+ \\
\text { flutamide } 250 \mathrm{mg} \text { TID for } 3 \text { months, } \\
\text { followed by RP }(\mathrm{n}=192)\end{array}$ & $\mathrm{RP}(\mathrm{n}=210)$ & $\begin{array}{ll}- & \text { PSM } \\
- & \text { Locally confined } \\
& \text { disease } \\
- & \text { Tumor grade and } \\
& \text { stage } \\
- & \text { LN involvement } \\
- & \text { Surgical } \\
& \text { complications } \\
- & \text { OS } \\
- & \text { RFS } \\
- & \text { Local recurrence- } \\
& \text { free survival } \\
- & \text { Distant metastases- } \\
& \text { free survival }\end{array}$ \\
\hline $\begin{array}{l}\text { Selli } \\
(2002)^{23}\end{array}$ & Italy & T2-T3, N0, M0 & $\begin{array}{c}431 \\
\text { (24 did not } \\
\text { undergo surgery, } \\
14 \text { not included } \\
\text { in analysis) }\end{array}$ & $\begin{array}{c}\text { Goserelin acetate } 3.5 \mathrm{mg} \mathrm{SC} \text { every } \\
28 \text { days + bicalutamide } 50 \mathrm{mg} \text { daily } \\
\text { for } 3 \text { months (short-term) or } 6 \\
\text { months (long-term), followed by RP } \\
\text { with bilateral PLND } \\
\text { (Short-term ADT: } n=143 \text {; long-term } \\
\text { ADT: } n=122 \text { ) }\end{array}$ & $\begin{array}{c}\text { RP with bilateral } \\
\text { PLND } \\
(\mathrm{n}=128)\end{array}$ & $\begin{array}{l}- \text { PSM } \\
-\quad \text { Tumor staging }\end{array}$ \\
\hline $\begin{array}{l}\text { Soloway } \\
(2002)^{24}\end{array}$ & $\begin{array}{c}\text { USA } \\
\text { Puerto Rico }\end{array}$ & $\begin{array}{c}\mathrm{cT} 2 \mathrm{~b} \\
\text { Normal bone scan } \\
\text { PSA }<50 \mathrm{ng} / \mathrm{ml} \\
\text { Age }<75\end{array}$ & $\begin{array}{c}303 \text { randomized } \\
\text { (21 not included } \\
\text { in analysis; } 7 \\
\text { did not undergo } \\
\text { surgery) }\end{array}$ & $\begin{array}{l}\text { Leuprolide } 7.5 \mathrm{mg} \text { IM monthly }+ \\
\text { flutamide } 250 \mathrm{mg} \text { TID for } 3 \text { months, } \\
\text { followed by RP }(\mathrm{n}=137)\end{array}$ & $\mathrm{RP}(\mathrm{n}=138)$ & $\begin{array}{ll}- & \text { PSM } \\
- & \text { PSA progression } \\
- & \text { Clinical progression } \\
- & \text { Cause-specific } \\
& \text { survival }\end{array}$ \\
\hline
\end{tabular}




\begin{tabular}{|c|c|c|c|c|c|c|}
\hline $\begin{array}{l}\text { Yee } \\
(2010)^{25}\end{array}$ & USA & $\begin{array}{c}\text { cT1-2 } \\
>10 \text {-year life } \\
\text { expectancy } \\
\text { Karnofsky } \\
\text { performance status } \\
=100\end{array}$ & $\begin{array}{l}148 \text { randomized } \\
\text { (11 did not } \\
\text { receive surgery, } \\
1 \text { not included in } \\
\text { analysis) }\end{array}$ & $\begin{array}{c}\text { Goserelin acetate } 3.6 \mathrm{mg} \text { SC monthly } \\
\text { + flutamide } 250 \mathrm{mg} \text { TID for } 3 \\
\text { months, followed by RP ( } \mathrm{n}=72)\end{array}$ & $\mathrm{RP}(\mathrm{n}=64)$ & $\begin{array}{ll}- & \text { PSM } \\
- & \text { Organ-confined } \\
& \text { disease } \\
- & \text { RFS }\end{array}$ \\
\hline \multicolumn{3}{|l|}{$\begin{array}{l}\text { Overall: } \\
\text { 11 RCTs }\end{array}$} & \multicolumn{4}{|c|}{$\begin{array}{l}2322 \text { patients randomized } \\
2125 \text { patients analyzed }\end{array}$} \\
\hline \multicolumn{7}{|c|}{ Adjuvant ADT } \\
\hline \multicolumn{7}{|c|}{ Androgen receptor antagonist } \\
\hline $\begin{array}{l}\text { Iversen } \\
(2010)^{26}\end{array}$ & $\begin{array}{c}\text { North } \\
\text { America } \\
\text { Europe } \\
\text { South } \\
\text { Africa } \\
\text { Australia } \\
\text { Israel }\end{array}$ & $\begin{array}{c}\text { Localized PCa: T1- } \\
\text { 2, N0/Nx) } \\
\text { Locally advanced } \\
\text { PCa: T3-4, or any } \\
\text { N; or and T N+ }\end{array}$ & $\begin{array}{c}4454 \\
(64 \text { also } \\
\text { received } \mathrm{RT})\end{array}$ & $\begin{array}{l}\text { RP followed by bicalutamide } 150 \mathrm{mg} \\
\text { for } 2 \text { years or until disease } \\
\text { progression } \\
(\mathrm{n}=2236)\end{array}$ & $\begin{array}{l}\text { RP followed by } \\
\text { placebo } \\
(\mathrm{n}=2218)\end{array}$ & $\begin{array}{ll}- & \text { OS } \\
- & \text { RFS } \\
- & \text { Prostate cancer } \\
& \text { death }\end{array}$ \\
\hline $\begin{array}{l}\text { Wirth } \\
(2004)^{27}\end{array}$ & $\begin{array}{l}\text { Germany } \\
\text { Austria }\end{array}$ & pT3-4, N0 & $\begin{array}{c}352 \\
\text { (43 not included } \\
\text { in analysis) }\end{array}$ & $\begin{array}{l}\text { RP with PLND followed by } \\
\text { flutamide } 250 \mathrm{mg} \text { TID }(\mathrm{n}=152)\end{array}$ & $\begin{array}{l}\text { RP with PLND } \\
\text { followed by } \\
\text { observation } \\
\quad(n=157)\end{array}$ & $\begin{array}{l}- \text { RFS } \\
-\quad \text { OS }\end{array}$ \\
\hline \multicolumn{7}{|c|}{ Synthetic estrogen } \\
\hline Byar $(1980)^{28}$ & USA & $\begin{array}{c}\text { Stage I: } \\
\text { Incidentally } \\
\text { diagnosed prostate }\end{array}$ & $\begin{array}{l}299 \\
\text { (52 not included } \\
\text { in analysis) }\end{array}$ & $\begin{array}{l}\text { RP followed by diethylstilbestrol } \\
\qquad 5 \mathrm{mg} \\
\text { (Stage 1: } \mathrm{n}=43 ; \text { Stage } 2: \mathrm{n}=82 \text { ) }\end{array}$ & $\begin{array}{l}\text { RP followed by } \\
\text { placebo }\end{array}$ & $\begin{array}{l}- \text { OS } \\
-\quad \text { Progression }\end{array}$ \\
\hline
\end{tabular}




\begin{tabular}{|c|c|c|c|c|c|c|}
\hline & & $\begin{array}{l}\text { cancer; no tumor } \\
\text { palpable rectally } \\
\text { Stage II: Palpable } \\
\text { tumor localized to } \\
\text { prostate gland } \\
\text { No bony } \\
\text { metastases }\end{array}$ & & & $\begin{array}{l}\text { (Stage 1: } n=46 \\
\text { Stage 2: } n=76)\end{array}$ & \\
\hline \multicolumn{7}{|c|}{ GnRH agonist or orchiectomy } \\
\hline $\begin{array}{l}\text { Messing } \\
(2006)^{29}\end{array}$ & USA & $\begin{array}{l}\text { cT1b or T2 with } \\
\text { lymph node } \\
\text { metastases } \\
\text { RP + PLND }\end{array}$ & $\begin{array}{c}100 \\
(2 \text { not eligible) }\end{array}$ & $\begin{array}{l}\text { RP with bilateral PLND followed by } \\
\text { goserelin } 3.6 \text { mg SC monthly until } \\
\text { local recurrence or orchiectomy } \\
(\mathrm{n}=47)\end{array}$ & $\begin{array}{l}\text { RP with bilateral } \\
\text { PLND followed } \\
\text { by observation } \\
(\mathrm{n}=51)\end{array}$ & $\begin{array}{ll}- & \text { OS } \\
- & \text { RFS } \\
- & \text { Disease-specific } \\
& \text { survival }\end{array}$ \\
\hline $\begin{array}{l}\text { Overall: } \\
4 \text { RCTs }\end{array}$ & & & \multicolumn{4}{|c|}{$\begin{array}{l}5205 \text { patients randomized } \\
5108 \text { patients analyzed }\end{array}$} \\
\hline
\end{tabular}

ADT: androgen-directed therapy; BID: twice daily; GnRH: gonadotropin-releasing hormone; HGPIN: high-grade prostatic intraepithelial neoplasia; IM: intramuscular; LN: lymph node; OS: overall survival; PAP: prostatic acid phosphatase; PCa: prostate cancer; PLND: pelvic lymph node dissection; PSA: prostate-specific antigen; PSM: positive surgical margins; RCT: randomized controlled trial; RFS: recurrence-free survival; RP: radical prostatectomy; SC: subcutaneous; TID: three times daily; WHO: World Health Organization. 